Thomas Jack

Bernadette E. Brent

Martin Boehne

Meike Müller

Katherina Sewald

Armin Braun

Armin Wessel

Michael Sasse

\section{Analysis of particulate contaminations of infusion solutions in a pediatric intensive care unit}

Received: 6 March 2009

Accepted: 31 October 2009

Published online: 18 February 2010

(C) The Author(s) 2010. This article is published with open access at Springerlink.com

T. Jack and B. E. Brent contributed equally to this work.

Electronic supplementary material

The online version of this article (doi:10.1007/s00134-010-1775-y) contains supplementary material, which is available to authorized users.
T. Jack (®) B B. E. Brent · M. Boehne

A. Wessel - M. Sasse

Department of Pediatric Cardiology

and Intensive Care Medicine,

Hannover Medical School,

Carl-Neuberg Straße 1,

30625 Hannover, Germany

e-mail: Thomasjack@gmx.de

Tel.: +49-511-5329112

M. Müller · K. Sewald · A. Braun Fraunhofer Institute for Toxicology and Experimental Medicine,

Hannover, Germany
Abstract Purpose: To examine the physical properties and chemical composition of particles captured by in-line microfilters in critically ill children, and to investigate the inflammatory and cytotoxic effects of particles on endothelial cells (HUVEC) and macrophages in vitro. Methods: Prospective, observational study of microfilters following their use in the pediatric intensive care unit. In vitro model utilizing cytokine assays to investigate the effects of particles on human endothelial cells and murine macrophages. Results: Twenty filter membranes from nine patients and five controls were examined by electron microscopy (EM) and energy dispersion spectroscopy (EDX). The average number of particles found on the surface of the used membranes was $550 \mathrm{~cm}^{2}$. EDX analysis confirmed silicon as a major particle constituent. Half of the filter membranes showed conglomerates containing an uncountable number of smaller particles. In vitro, glass particles were used to mimic the high silicon content particles. HUVEC and murine macrophages were exposed to different contents of particles, and cytokine levels were assayed to assess their immune response. Levels of interleukin-1beta, interleukin-6, interleukin-8, and tumor necrosis factor alpha were suppressed. Conclusions: Particle contamination of infusion solutions exists despite a stringent infusion regiment. The number and composition of particles depends on the complexity of the applied admixtures. Beyond possible physical effects, the suppression of macrophage and endothelial cell cytokine secretion in vitro suggests that microparticle infusion in vivo may have immune-modulating effects. Further clinical trials are necessary to determine whether particle retention by in-line filtration has an influence on the outcome of intensive care patients.

Keywords Contamination · Particle . Immune system - In-line filtration . Infusion therapy

\section{Introduction}

One million particles per patient may be infused daily in an intensive care setting, where a potential risk appears against the background of debilitation and impaired host responses $[1,2]$. Mechanisms of particle damage to various organs have been postulated, including effects on microcirculation causing thrombi and granuloma formation [3-5]. Use of in-line filtration almost completely prevents particulate infusion [6]. Recent studies have evaluated the clinical effect of in-line filtration and showed significant reduction in thrombophlebitis [7] and a trend towards reduction of complications in neonates such as sepsis, thrombosis, and necrotizing enterocolitis [8]. 
To evaluate the effects of microfilters in the pediatric intensive care unit (PICU), we carried out detailed examinations of filters after their use. Electron microscopy (EM) visualized particles adhering to the membrane, and energy dispersion spectroscopy (EDX) revealed their chemical compositions [9]. Based on these data immune-modulating effects on human umbilical vein endothelial cells (HUVEC) and murine macrophages (RAW 264.7) were analyzed in vitro.

\section{Materials and methods}

Prior to this study, the infusion regiment in the PICU was optimized to prevent precipitation and incompatibilities using a computer-based analysis. Solutions and therapeutics were prepared according to the manufacturers' recommendations. Approval by the ethics committee and parental consent were obtained.

\section{EM and EDX}

Twenty-five Pall ELD96LLCE/NEO96E filters with $0.2 \mu \mathrm{m}$ pore size (Pall, Dreieich, Germany) were analyzed. Twenty filters from nine patients were randomly chosen after $72 \mathrm{~h}$. Five unused filters served as controls (see Table 1, ESM). For detailed information see ESM.

\section{Cell culture}

To simulate the in vivo situation, glass particles (2$20 \mu \mathrm{m})$ were chosen to mimic the silicon content of particles found on the filters. Contamination with lipopolysaccharide (LPS) was excluded. Inflammatory effects were analyzed on RAW 264.7 (gamma NO-, ATCC CRL-2278) and HUVEC (CC2517). Cytotoxic particle load was determined by release of adenylatkinase (ToxiLight test) and lactate-dehydrogenase (LDH-cytotoxicity test). Experiments were performed at subtoxic loads. Cells were incubated with glass particles at contents from 0 to $500 \mu \mathrm{g} / \mathrm{ml}$. Release of interleukin 1-beta (IL-1 $\beta$ ), interleukin-6 (IL-6), interleukin-8 (IL-8), and tumor necrosis factor alpha $(\mathrm{TNF} \alpha)$ was measured after 4,8 , and $24 \mathrm{~h}$ with ELISA kits for IL-1 $\beta$ (DY201), IL-6 (DY406), IL-8 (DY208), and TNF $\alpha$ (DY410; all kits by R\&D Duoset).

Cells were additionally incubated with $1 \mu \mathrm{g} / \mathrm{ml} \mathrm{LPS}$, and HUVEC cells with $1 \mathrm{ng} / \mathrm{ml} \mathrm{TNF} \alpha$ as well. Results of ELISA are given as the median of repeated determinations. ToxiLight test results reflect the mean of four trials and considered values within three standard deviations of the controls as nontoxic. Statistics were processed by Dunnett's test [10].

\section{Results}

EM and EDX analysis

The average number (range) of particles on the surface of the negative controls was 45.6 particles $/ \mathrm{cm}^{2}$ (6-93 particles $\left./ \mathrm{cm}^{2}\right)$. Used filters showed a mean of 550 particles/ $\mathrm{cm}^{2}$ (8-1,993 particles/ $\left.\mathrm{cm}^{2}\right)$, which was significantly higher than the mean particle load of controls $(P<0.001)$.

Particle size ranged from 5 to $>100 \mu \mathrm{m}$ with the majority between 5 and $50 \mu \mathrm{m}$. EDX analysis detected silicon, carbon, oxygen, sodium, chloride, potassium, calcium, magnesium, iron, and aluminum. Phosphorus, thallium, fluorine, chromium, copper, zinc, sulfur, barium, and nickel were seldom found. Only carbon and oxygen may be part of the membrane itself. Gold was added during preparation. Silicon was the most frequently detected element in analysis of individual particles. These particles were notable for their angular shape and crystalline appearance (Fig. 1a, b).

Fifty percent of analyzed filters showed conglomerates on the surfaces, containing uncountable numbers of particles. Figure 1c shows a conglomerate, detected on a filter used for parenteral nutrition and heparin (filter 12, Table 1, ESM). Parenteral nutrition was highly concentrated with an osmolarity $>1,300 \mathrm{mosm} / \mathrm{l}$. EDX analysis revealed different elements as components of the conglomerate (e.g., carbon, sodium, potassium). It demonstrates the spectrum of elements and is representative of other analyzed particles. Results of particle counts and data of the applied fluids/therapeutics are shown in Table 1 of the ESM. Data suggest a correlation between the complexity of the infusion regiment and the particle load (Fig. 1, ESM).

Cell culture (HUVEC/RAW 264.7)

\section{Cytotoxicity}

ToxiLight and LDH-cytotoxicity tests found that particle loads $>500 \mu \mathrm{g} / \mathrm{ml}$ were toxic in RAW 264.7 and HUVEC. For detailed information on cytotoxicity tests, see ESM.

HUVEC and IL-8 After incubation of HUVEC with glass particles, IL-8 increased significantly in samples of $300 \mu \mathrm{g}(P<0.05)$ and $500 \mu \mathrm{g}(P<0.01)$ particles $/ \mathrm{ml}$. Additional stimulation of HUVEC with $1 \mu \mathrm{g} / \mathrm{ml}$ LPS or $1 \mathrm{ng} / \mathrm{ml} \mathrm{TNF} \alpha$ led to a 10 -fold increase in IL- 8 in samples incubated with particle concentrations above $300 \mu \mathrm{g} / \mathrm{ml}$. Samples with particle dilution of $10 \mu \mathrm{g} / \mathrm{ml}$ and above showed significant suppression of IL-8 at 4 and $8 \mathrm{~h}$ after incubation with LPS (Fig. 2, ESM). Increased IL-8 levels were detected for 300 and $500 \mu \mathrm{g} / \mathrm{ml}$ (data not shown).

HUVEC and IL- $1 \beta$ After 8 and $24 \mathrm{~h}$ incubation, concentrations of IL-1 $\beta$ were significantly suppressed 

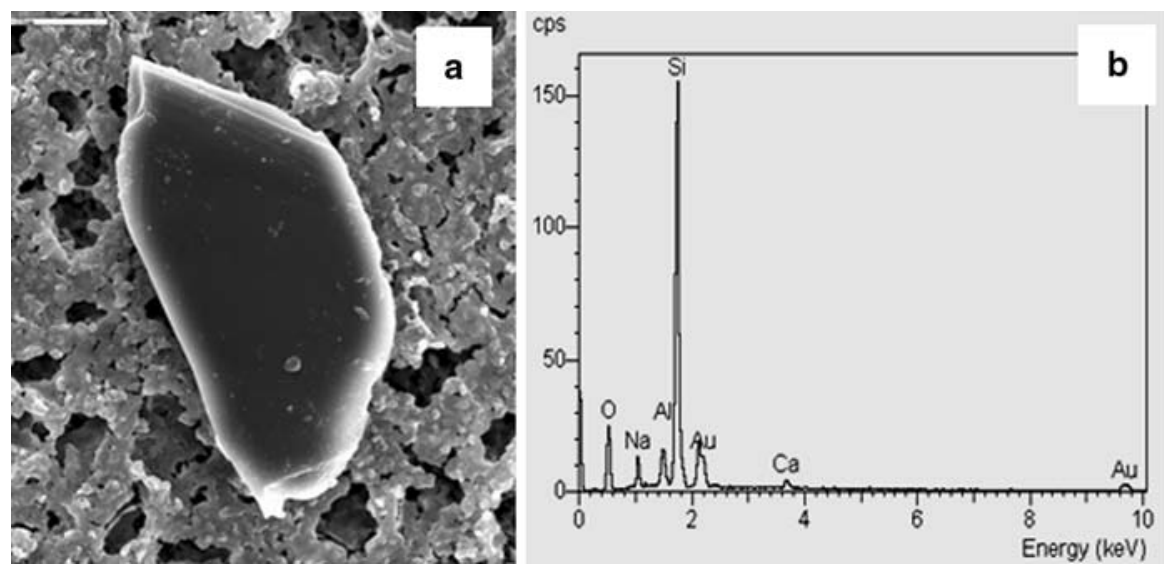

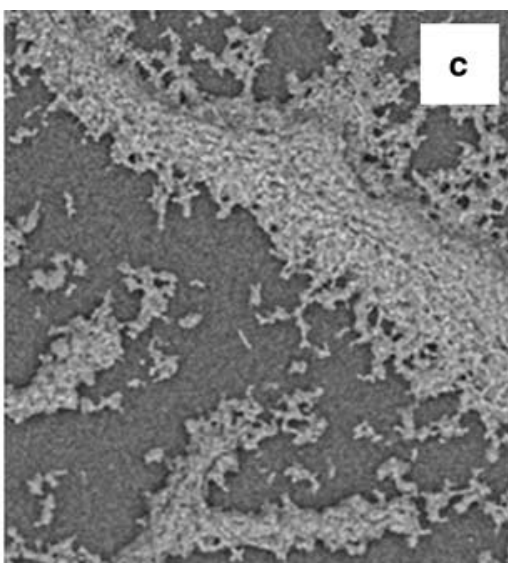

Fig. 1 Particle (a) with corresponding EDX analysis (b) and conglomerate (c) found by electron microscopy on the surface of different filters. Presented filter (a) was used for the application of bolus injections of multiple different therapeutics via a central venous line. The size of the particle is approximately $40 \times 20 \mu \mathrm{m}$. It shows the representative angular shape and crystalline appearance. In addition to the large particle, many smaller particles and the incipient blockage of the filter membrane are apparent. The corresponding $\operatorname{EDX}$ (b) revealed silicon as the major chemical element. The second filter (c) was used for high osmolar parenteral nutrition $(>1,300 \mathrm{mosmol} / \mathrm{l})$ via a central venous catheter in a 4-month-old infant after liver transplantation. The EDX analysis revealed carbon, sodium, chloride, potassium, selene, silicon, and phosphate as components of the conglomerate

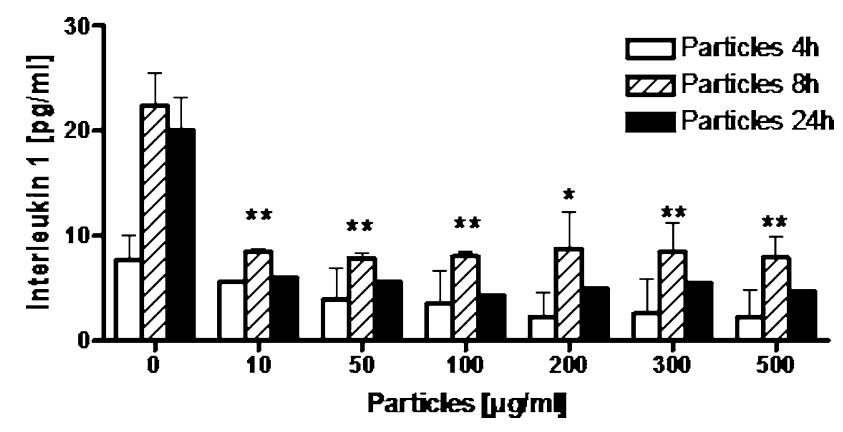

Fig. 2 Interleukin-1beta concentration (pg/ml) after 4, 8 and $24 \mathrm{~h}$ incubation period of HUVEC with different glass particle concentrations. After $8 \mathrm{~h}$ incubation with glass particles the release of interleukin-1beta was significantly reduced independent from particle content. Values are mean of four separate assays \pm standard deviation of all samples. ${ }^{*} p<0.05 ; * * p<0.01$

$(P<0.05)$ (Fig. 2). Adding $1 \mu \mathrm{g} / \mathrm{ml}$ LPS did not change the IL-1 $\beta$ secretion. Also stimulation of HUVEC with $1 \mathrm{ng} \mathrm{TNF} \alpha / \mathrm{ml}$ revealed no significant variation after 4 and $8 \mathrm{~h}$. Samples could not be analyzed for IL- $1 \beta$ concentration after $24 \mathrm{~h}$ since over $80 \%$ of cells died.

RAW 264.7 and TNF $\alpha$ In macrophages, control samples from 4 to $24 \mathrm{~h}$ showed a high spontaneous release of $\mathrm{TNF} \alpha$. Increasing the particle load resulted in reduction of $\mathrm{TNF} \alpha$ after $4-8 \mathrm{~h}$. Only after incubation of $24 \mathrm{~h}$ was a significant dose-related stimulation detected $(P<0.01)$ (data not shown).

RAW 264.7 and IL-6 Significant suppression of IL-6 concentration occurred after an incubation period of $8 \mathrm{~h}$ with a particle load of $10 \mu \mathrm{g} / \mathrm{ml}$. In the remaining samples, incubation of RAW with glass particles did not show any dose-related release of IL-6. Incubation with $1 \mu \mathrm{g} / \mathrm{ml}$ LPS for $4 \mathrm{~h}$ revealed a doubling of IL-6 concentration without any dose-related effects of particles. After $24 \mathrm{~h}$ a significant reduction of IL-6 was detected (data not shown).

\section{Discussion}

Our results confirmed the existence of particulate contamination in infusions despite a stringent infusion regime in the PICU. Different contents of particles were found, and data suggest that particle exposure is dependent on the complexity of infusions and medications. These findings are in keeping with the results of Mehrkens et al. [1], who showed that bolus injections mainly increase particulate contamination of the administered fluids.

Considering the detection limit of $5 \mu \mathrm{m}$, the detected amount underestimates the particle exposure. Fifty percent of the analyzed membranes showed conglomerates containing uncountable numbers of particles. Smaller particles were retained in the three-dimensional meshwork of the membrane and were disregarded. Most particles were between 5 and $50 \mu \mathrm{m}$, which is more than the diameter of lung and tissue capillaries [11] and may cause obstruction. This supports the findings of Puntis et al. [4] that particles cause granulomatous arteritis after parenteral nutrition as demonstrated by post-mortem study of 73 infants.

In accordance with other authors, we identified silicon as a major chemical component [12], which originates mainly from storage in glass ampoules [13]. 
In addition to mechanical obstruction, inflammatory response of different organ systems after particle exposure is possible $[3,14,15]$. To mimic these mechanisms, we exposed macrophages and endothelial cells to particles similar to those found on the filters. Our experiments with endothelial cells showed significant suppression of IL- $1 \beta$ after incubation with particles for 8 and $24 \mathrm{~h}$. Comparable results were assessed for IL-8. This effect was aggravated by LPS. In macrophages, different particle loads suppressed the secretion of $\mathrm{TNF} \alpha$. Similar effects were evident for IL-6, which was significantly suppressed after $8 \mathrm{~h}$ incubation. Increased IL-8 was found after incubation with $300-500 \mu \mathrm{g} / \mathrm{ml}$ particles. This was probably due to cytotoxicity as was seen for comparable particle contents in pre-tests.

Previously published data suggest an activation of the immune system by particles [15]. In contrast, our experiments showed a reduced cytokine release. Immune paralysis is an accepted phenomenon in sepsis or after ischemia or trauma, as confirmed by clinical and experimental studies [16-19]. The importance of the exact regulation of the chemokine release and the balance of pro-inflammatory and anti-inflammatory mediators in this phase of the disease is not exactly clear. Small changes may have an influence and alter the process of overcoming the disease. Foreign particles may interfere with this phase of the disease when the patient is especially vulnerable.

Lehr et al. [5] demonstrated that stress increases the harmful effects of particles. Their animal model revealed a reduction in capillary density in post-ischemic muscles after particle infusion, in cases without preceding ischemia, no change in density was detectable.
A documented benefit of filtration is the prevention of infusion phlebitis [7]. Less information exists for the influence of filtration on severely ill patients. One singlecenter trial on 88 preterm newborns showed a trend toward decreased morbidity in the treatment group [8]. However, the incidence of sepsis could not be reduced by in-line filtration [20].

According to the data of a preceding analysis, $70 \%$ of our PICU patients were provided with a central-venous line with three lumina for standardized infusion therapy. Despite this standard, our examinations demonstrate that particle exposure continues to be an unpredictable risk for patients receiving infusion therapy.

Review of literature and our data suggest that particles are capable of modulating cytokine secretion and may exert harmful effects beyond mechanical obstruction. Whether particles affect the outcome of PICU patients has to be further evaluated.

Acknowledgments We thank Dr. Capewell from the Pall Corporation for his support and $\mathrm{B}$. Braun and Pall Corporations for the financial support. This study was funded by Pall Corporation, Dreieich, Germany and B. Braun Corporation, Melsungen, Germany. Dr. Jack and Dr. Sasse received lecture and travel fees form Pall Corporation and B. Braun Corporation. Dr. Boehne received travel fees from Pall Corporation. All authors indicate that their institutions have received research grants from Pall Corporation and B. Braun Corporation.

Open Access This article is distributed under the terms of the Creative Commons Attribution Noncommercial License which permits any noncommercial use, distribution, and reproduction in any medium, provided the original author(s) and source are credited.

\section{References}

1. Mehrkens HH, Klaus E, Schmitz JE (1977) Possibilities of material contamination due to additional injections. Klin Anasthesiol Intensivther 14:106-113

2. Walpot H, Franke RP, Burchard WG, Agternkamp C, Müller FG, Mittermayer C, Kalff G (1989) Particulate contamination of infusion solutions and drug additives within the scope of long-term intensive therapy. 1: Energy dispersion electron images in the scanning electron microscopeREM/EDX. Anaesthesist 38:544-548

3. Walpot H, Franke RP, Burchard WG, Agternkamp C, Müller FG, Mittermayer C, Kalff G (1989) Particulate contamination of infusion solutions and drug additives in the framework of long-term intensive therapy. 2: An animal model. Anaesthesist 38:617-621
4. Puntis JW, Wilkins KM, Ball PA, Rushton DI, Booth IW (1992) Hazards of parenteral treatment: do particles count? Arch Dis Child 67:1475-1477

5. Lehr HA, Brunner J, Rangoonwala R, Kirkpatrick CJ (2002) Particulate matter contamination of intravenous antibiotics aggravates loss of functional capillary density in postischemic striated muscle. Am J Respir Crit Care Med 165:514-520

6. Schaefer SC, Bison PA, Rangoonwala R, Kirckpatrick CJ, Lehr HA (2008) $0.2 \mu \mathrm{m}$ in-line filters prevent capillary obstruction by particulate contaminants of generic antibiotic preparations in postischemic muscle. Chemother J 17:172-178

7. Falchuk KH, Peterson L, McNeil BJ (1985) Microparticulate-induced phlebitis: its prevention by in-line filtration. N Engl J Med 312:78-82
8. van Lingen RA, Baerts W, Marquering AC, Ruijs GJ (2004) The use of in-line intravenous filters in sick newborn infants. Acta Paediatr 93:658-662

9. Brent BE, Müller M, Jack T (2007) Harmful effects of infused particles. Abstract P 44.3.1004. 5th World Congress on Pediatric Critical Care, June 24-28, Geneva, Switzerland

10. Dunnett CW (1955) A multiple comparison procedure for comparing several treatments with a control. J Am Stat Assoc 50:1096-1121

11. Levick JR (2003) Introduction to cardiovascular physiology, 2nd edn. Oxford University Press, Oxford

12. Oie S, Kamiya A (2005) Particulate and microbial contamination in in-use admixed parenteral nutrition solutions. Biol Pharm Bull 28:2268-2270 
13. Yorioka K, Oie S, Oomaki M, Imamura A, Kamiya A (2006) Particulate and microbial contamination in in-use admixed intravenous infusions. Biol Pharm Bull 29:2321-2323

14. Hellinger A, Piotrowski J, Konerding MA, Burchard WG, Doetsch N, Peitgen K, Erhard J, Reidemeister JC (1997) Impact of particulate contamination in crystalloid cardioplegic solutions: studies by scanning and transmission electron microscopy. Thorac Cardiovasc Surg 45:20-26

15. Schulz H, Harder V, Ibald-Mulli A, Khandoga A, Koenig W, Krombach F, Radykewicz R, Stampfl A, Thorand B, Peters A (2005) Cardiovascular effects of fine and ultrafine particles. J Aerosol Med 18:1-22
16. Heidecke CD, Weighardt $\mathrm{H}$, Hensler $\mathrm{T}$, Bartels H, Holzmann B (2000) Immune paralysis of T-lymphocytes and monocytes in postoperative abdominal sepsis: correlation of immune function with survival. Chirurg 71:159-165

17. Pinheiro da Silva F, Nizet V (2009) Cell death during sepsis: integration of disintegration in the inflammatory response to overwhelming infection. Apoptosis 14:509-521

18. Wiersinga WJ, van't Veer C, van den Pangaart PS, Dondorp AM, Day NP, Peacock SJ, van der Poll T (2009) Immunosuppression associated with interleukin-1R-associated-kinase-M upregulation predicts mortality in Gram-negative sepsis (melioidosis). Crit Care Med 37:569-576
19. Kremer JP, Jarrar D, Steckholzer U, Ertel W (1996) Interleukin-1,-6 and tumor necrosis factor-alpha release is down-regulated in whole blood from septic patients. Acta Haematol 95:268273

20. van den Hoogen A, Krediet TG, Uiterwaal CS, Bolenius JF, Gerards LJ, Fleer A (2006) In-line filters in central venous catheters in a neonatal intensive care unit. J Perinat Med 34:71-74 